\title{
http://bjas.journals.ekb.eg \\ Prognostic and Predictive Value of Serum b-Type Natriuretic Peptide in Early Mortality and Morbidity of Children with Congenital Heart Disease after Open Heart Surgery
}

\author{
R.S.Arafa ${ }^{1}$,S.E.Azab ${ }^{2}$, S.S.Sheta ${ }^{1}$, H.M.Kamal ${ }^{3}$ and M.S.Nassar ${ }^{1}$ \\ ${ }^{1}$ Pediatrics Dept., Faculty of Medicine, Benha Univ., Benha, Egypt \\ ${ }^{2}$ Cardio thorathic surgery Dept., Faculty of Medicine, Benha Univ., Benha, Egypt \\ ${ }^{3}$ Clinical and Chemical Dept., Faculty of Medicine, Benha Univ., Benha, Egypt \\ E-Mail:ahmed2356@gmail.com
}

\begin{abstract}
Epilepsy is a common neurodegenerative disease with an increasing morbidity. Clinical treatment of epilepsy includes symptomatic treatment, etiological treatment, surgery and prevention. The aim of the present study was to determine the effects of antiepileptic drugs (AEDs) on serum folate and vitamin B12 in various epileptic patients. Brain type natriuretic peptide (BNP) is a cardiac hormone that is secreted mainly by the ventricles in response to volume expansion and pressure load. It can predict post-operative complications after open cardiac surgery in children. We sought to evaluate the prognostic and predictive values of proBNP in children after heart surgery.This study was a prospective observational study conducted on patients with congenital heart diseases admitted to the pediatric cardiology department in Cairo University Children Hospital and Atfal Maser Hospital during 2 years interval from February 2016 to March 2018.The study was conducted on 45 cases age range from 0 up to 12 years, who are previously listed and prepared for open heart surgery. Brain natriuretic peptides determinations might be a useful tool for clinicians caring for infants and children after surgical intervention for congenital heart disease. The aim of this study is to compare perioperative changes in plasma brain natriuretic peptides in children undergoing open heart surgery and to evaluate effect of cardiopulmonary bypass on proBNP levels. The results in the present study revealed preoperative BNP assay of the 45 cases with a mean $239.6+/-829.7 \mathrm{pg} / \mathrm{ml}($ median $=32.0 \mathrm{pg} / \mathrm{ml})$ and postoperative BNP assay with a mean $1412.2+/-1279.1 \mathrm{pg} / \mathrm{ml}$.In the current study, a comparison between preoperative and postoperative BNP values was done and revealed the total mean difference between pre and postoperative BNP was with a mean $1,172.5838 \mathrm{pg} / \mathrm{ml}+/-936.6379 \mathrm{pg} / \mathrm{ml}$ with a significant p-value $(0.00)$. We have found many studies in agreement with the results in the current study which have showed increase in BNP levels after surgery. ProBrain natriuretic peptides determinations might be a useful tool for clinicians caring for infants and children after surgical intervention for congenital heart disease. Mechanical ventilation duration, inotropic score calculation as well as Core-peripheral temperature difference are of value when correlated to postoperative BNP measurements. ProBNP cut off values in predicting poor outcome are of paramount importance.
\end{abstract}

Keywords: Serum ProBNP; Cross Clamping time, Time CPB, Inotropic score post-operative, Time stay in MV, Time stay in ICU post-operative .

\section{Introduction}

ProBrain type natriuretic peptide (BNP) is a cardiac hormone with diuretic, natriuretic, and vasodilator properties that are secreted mainly by the ventricles in response to volume expansion and pressure load [1].

The use of proBNP as an indicator of RV dysfunction in children with pulmonary hypertension undergoing congenital heart surgery remain largely unknown.it was reported that plasma BNP levels increasing immediately after congenital heart surgery [2] .The measurement of serum proBNP is increasingly used to aid diagnosis, assess prognosis, and conduct risk stratification in adults with congestive heart failure [3].

$\mathrm{BNP}$ is synthesized as pre-pro hormone, consisting of 108 amino acids; processing releases the biologically active 32-amino acid peptide and an amino-terminal fragment (NT-pro BNP).The NT-pro $\mathrm{BNP}$ represents the $\mathrm{N}$-terminal fragment of pro$\mathrm{BNP}$, the precursor of the biologically active BNP [4].

Unlike BNP, NT-pro BNP circulates at considerable concentrations in human plasma, is

stable at room temperature for $>24$ hours, and can easily be detected and quantified by immunoassay [5].

These factors confer its potential as an additional tool in the assessment of ventricular systolic dysfunction [6].

The plasma BNP level is useful in congenital heart 110The Journal of Tehran University Heart Centre diseases assessment, left and right ventricular dysfunction, congestive heart failure diagnosis and severity, and functional status in patients (adults and paediatrics) with pulmonary hypertension [7].

There is scarce information available concerning the plasma concentrations of BNP in children with congenital heart diseases after open heart surgery. The purpose of this study was to investigate the prognostic validity of serum BNP in paediatric patients with congenital heart diseases after surgery for an evaluation of mortality and morbidity. Heart failure appears to result not only from cardiac overload or injury but also from a complex interplay among genetic, neurohormonal, inflammatory, and biochemical changes acting on cardiac myocytes, the cardiac interstitial, or both. An 
increasing number of enzymes, hormones, biologic substances, and other markers of cardiac stress and malfunction, as well as myocyte injury collectively referred to as biomarkers appear to have growing clinical importance [8].

Colleagues properly concluded that "strategies to reduce neurohormonal levels for mortality and morbidity are at present premature and not justified." They concluded that we have not yet achieved the level of sophistication that is necessary to reliably use biomarkers to optimize clinical care for patients with heart failure [9].

One might envision that clinicians could use combinations of different biomarkers that reflect different aspects of the disease process to optimize multiple facets of patient care, or use genetic biomarkers to provide an optimized pharmacogenomics approach, or perhaps even use screening biomarkers to select specific types of therapies However, biomarker-guided strategies will have to be validated extensively in long-term epidemiological studies, as well as in clinical studies that demonstrate the added value of this type of approach over and above the clearly established benefits that are provided by the current best approach to the management of heart failure [9].

\section{Subjects\& methods}

\subsection{Subjects}

The study was conducted on 45 cases, who are previously listed and prepared for open heart surgery. Patients' age ranged from 0 up to 12 years of age and duration of study: 2 years from February 2016 to March 2018.

Before the patient was enrolled in the study, informed consent was obtained from each neonate's father.

\subsection{Methods}

All patients were subjected to:

\section{Preoperative assessment}

1. Demographic and baseline clinical data recordings regarding age, sex, heart rate, blood pressure, weight and length or height.

2. Preoperative plasma proBNP measurement.

\section{Intraoperative assessment}

Included:

1. Bypass time.

2. Ischemic time.

3. Incidence of cardiac arrest.

\section{Postoperative assessment included}

1-24 hours post cardiopulmonary bypass plasma probnp measurement.

2-Postoperative heart rate \& blood pressure at 1,6,12 and 24 hours.

3-Low cardiac output (co) parameters: peripheral perfusion (core-peripheral temp.), oliguria, metabolic acidosis on 2 successive blood gas measurements in the first 24 hours postoperative.

4-Length of mechanical ventilation ( $p m v$ defined as $\geq$ 48 hours as defined by alexander et al., 2014).

5-Pediatric cardiac intensive care unit (pcicu) stay (prolonged icu stay defined as $\geq 7$ days as defined by alexander et al., 2014).

6-Vasoactive inotropic score at pcicu admission, after 6 and 12 hours. (vasoactive inotropic score, calculated as dopamine dose $\mathrm{mcg} / \mathrm{kg} / \mathrm{min}+$ dobutamine dose $\mathrm{mcg} / \mathrm{kg} / \mathrm{min}+$ vasopressin dose units $/ \mathrm{kg} / \mathrm{min}$ x $10,000+$ milrinone dose $\mathrm{mcg} / \mathrm{kg} / \mathrm{min}$ $\mathrm{x} 10+$ epinephrine dose $\mathrm{mcg} / \mathrm{kg} / \mathrm{min} \mathrm{x} 100+$ norepinephrine dose $\mathrm{mcg} / \mathrm{kg} / \mathrm{min} \mathrm{x}$ 100) . (10).

7-The need for peritoneal dialysis (PD).

8-Mortality cases.

\section{Exclusion criteria}

1. Patients presenting with heart failure secondary to rheumatic heart disease or other acquired heart lesions

2. Patients presenting with pulmonary hypertension secondary to other causes rather congenital heart diseases as chest problems or sarcoidosis etc....

3. Infective endocarditis (surgical emergency).

\subsection{Sampling}

$4 \mathrm{ml}$ of blood were withdrawn from each case pre and post operation, two $\mathrm{ml}$ blood were obtained and were immediately placed into plastic collection tubes containing ethylenediaminetetraacetic acid sodium and centrifuged at $3000 \mathrm{rpm}$ for 10 minutes at 4oc.

\section{Storage}

Samples, stored at $2-8^{\circ} \mathrm{C}$ were tested within 24 hours of collection. Whole plasma samples, stored at room temperature were tested within 4 hours of collection. If samples cannot be tested within the given times for room temperature or $2-8^{\circ} \mathrm{C}$ storage, they may be separated by centrifugation and frozen for up to 3 months at $-20^{\circ} \mathrm{C}$ or below in plastic tubes.

\subsection{Statistical methods}

Data were statistically described in terms of mean \pm standard deviation $\pm \mathrm{SD}$ ), median and range, or frequencies (number of cases) and percentages when appropriate. Comparison of numerical variables between pre and post values was done using paired $t$ test. Correlation between various variables was done using Pearson moment correlation equation for linear relation in normally distributed variables and Spearman rank correlation equation for non-normal variables/non-linear monotonic relation. Accuracy was represented using the terms sensitivity, and specificity. Receiver operator characteristic (ROC) analysis was used to determine the optimum cut off value for the studied diagnostic markers. $p$ values less than 0.05 was considered statistically significant. All statistical calculations were done using computer 
program SPSS (Statistical Package for the Social Science; SPSS Inc., Chicago, IL, USA) release 15 for Microsoft Windows (2006).

\section{Results}

The study was conducted on 45 cases who are previously listed and prepared for open heart surgery during the duration from (February 2016 to March 2018).

Patients' age ranged from 2 months up to 12 years old. Median age $=25$ months, mean age of cases $=24.98+/-32.20$ months. Male to female ratio was 19:26, males $(42.2 \%)$ and females $(57.8 \%)$.Mortality cases recorded were 6

Table (1) Total mean difference between pre and $24 \mathrm{hrs}$ postoperative BNP.

\begin{tabular}{lccc}
\hline Item & Mean & Std. Deviation & p value \\
\hline BNP-0 - BNP 24h & $-1,172.5838$ & 936.6379 & 0.000 \\
\hline
\end{tabular}

BNP-0 $=$ preoperative BNP, BNP 24h $=24 \mathrm{hrs}$. Postoperative BNP.

This table showed total mean difference between pre and post BNP in all 45 cases with a *: Statistically significant at $\mathrm{p} \leq 0.05$

Table (2) Correlation of 24 hrs. Postoperative BNP with ischemic and bypass times.

\begin{tabular}{lll}
\hline Item & r-value & p-value \\
\hline Bypass time & 0.313 & 0.037 \\
\hline
\end{tabular}

Correlation between 24 hrs. postoperative BNP and bypass and ischemic times. P-value showed significance and r-value showed significant correlation. *: Statistically significant at $\mathrm{p} \leq 0.05$.

Table (3) Correlation of 24 hrs. postoperative BNP with core-peripheral temp., perfusion and urine output (24 hrs. postoperative).

\begin{tabular}{lll}
\hline Item & r-value & p-value \\
\hline Core-peripheral temp. & 0.419 & 0.010 \\
Peripheral perfusion & 0.028 & 0.868 \\
Urine output & 0.060 & 0.725 \\
\hline
\end{tabular}

Correlation between 24 hrs. postoperative BNP and low cardiac output parameters. P-value was significant to core-peripheral temp. $(p=0.01)$. $r$-value showed low positive correlation between $24 \mathrm{hrs}$. postoperative BNP and core-peripheral temp.
( $\mathrm{r}=0.419)$, while between 24 hrs. postoperative BNP and urine output of 1 st 24 hours postoperative and mean peripheral perfusion of 1 st 24 hours r-value showed no significant correlation.

Table (4) Correlation of 24 hrs. postoperative BNP with inotropic score at admission, 6 and 12 hrs. postoperative.

\begin{tabular}{lll}
\hline Item & r-value & p-value \\
\hline Inotropic score at ICU admission & 0.273 & 0.102 \\
Inotropic score 6 hrs. postoperative & 0.342 & 0.038 \\
Inotropic score 12 hrs. postoperative & 0.364 & 0.027 \\
\hline
\end{tabular}

Correlation between $24 \mathrm{hrs}$. postoperative BNP and inotropic score of ICU admission, 6 hrs. and 12 hrs. postoperative. P-value was significantly correlated to inotropic score of 6 and $12 \mathrm{hrs}$. postoperative $(\mathrm{p}=0.038,0.027)$ respectively. $\mathrm{r}$-value showed low positive correlation between $24 \mathrm{hrs}$. postoperative BNP and inotropic scores 6 and $12 \mathrm{hrs}$ postoperative $(r=0.342,0.364)$ respectively. While $r$ value of inotropic score of ICU postoperative admission showed no significant correlation. *: Statistically significant at $\mathrm{p} \leq 0.05$.

Table (5 )Correlation of 24 hrs. postoperative BNP with mechanical ventilation duration and ICU stay.

\begin{tabular}{lll}
\hline Item & r-value & p-value \\
\hline MV duration & 0.538 & 0.001 \\
ICU stay & 0.448 & 0.002 \\
\hline
\end{tabular}


Correlation between $24 \mathrm{hrs}$. postoperative BNP and mechanical ventilation duration and ICU stay. Pvalue was significant to MV duration $(p=0.001)$ and showed significance to ICU stay. r-value of MV duration showed positive correlation $(\mathrm{r}=0.363)$, and $\mathrm{r}$ value of ICU stay showed significant correlation. * Statistically significant at $\mathrm{p} \leq 0.05$

Table (6) Relation between arrest and intraoperative parameters $(n=45)$.

\begin{tabular}{|c|c|c|c|c|}
\hline \multirow[t]{2}{*}{ Intraoperative parameters } & \multicolumn{2}{|c|}{ Arrest } & \multirow[t]{3}{*}{ Test of sig. } & \multirow[t]{3}{*}{$\mathbf{P}$} \\
\hline & \multirow[t]{2}{*}{ No $(n=39)$} & \multirow[t]{2}{*}{ Yes $(n=6)$} & & \\
\hline Time CPB(Minutes) & & & & \\
\hline Min. - Max. & $48.0-160.0$ & $84.0-155.0$ & $\mathrm{t}=1.321$ & 0.193 \\
\hline Mean \pm SD. & $95.77 \pm 20.88$ & $108.17 \pm 25.02$ & & \\
\hline Median & 90.0 & 102.50 & & \\
\hline \multicolumn{5}{|l|}{ Cross clamp time (m) } \\
\hline Min. - Max. & $40.0-135.0$ & $48.0-125.0$ & $\mathrm{U}=92.50$ & 0.423 \\
\hline Mean \pm SD. & $61.31 \pm 23.73$ & $67.17 \pm 29.36$ & & \\
\hline Median & 50.0 & 55.0 & & \\
\hline
\end{tabular}

t: Student t-test U: Mann Whitney test

$\mathrm{p}$ : $\mathrm{p}$ value for comparing between the two studied groups

Correlation between arrested and intraoperative patameters (CPB, Cross clamp).p-Value was insignificant to both

CPB ( $p=0.193)$ and Cross clamp time $(p=0.423)$.

*: Statistically significant at $\mathrm{p} \leq 0.05$

Table (7) Relation between arrest and postoperative outcome $(n=45)$.

\begin{tabular}{|c|c|c|c|c|}
\hline \multirow[t]{2}{*}{ Postoperative outcome } & \multicolumn{2}{|c|}{ Arrest } & \multirow[t]{2}{*}{$\mathbf{U}$} & \multirow[t]{2}{*}{$\mathbf{P}$} \\
\hline & No $(n=39)$ & Yes $(n=6)$ & & \\
\hline \multicolumn{5}{|l|}{ Post-operative } \\
\hline \multicolumn{5}{|l|}{ ICU(day) } \\
\hline Min. - Max. & $0.50-18.0$ & $2.0-7.0$ & $46.0^{*}$ & $0.016^{*}$ \\
\hline Mean \pm SD & $6.83 \pm 3.86$ & $4.0 \pm 1.79$ & & \\
\hline Median & 6.0 & 3.50 & & \\
\hline \multicolumn{5}{|l|}{ MV(Hours) } \\
\hline Min. - Max. & $12.0-100.0$ & $12.0-100.0$ & 68.0 & 0.107 \\
\hline Mean \pm SD & $32.92 \pm 27.74$ & $57.0 \pm 33.91$ & & \\
\hline Median & 18.0 & 55.0 & & \\
\hline
\end{tabular}

U: Mann Whitney test

$\mathrm{p}$ : $\mathrm{p}$ value for comparing between the two studied groups $\mathrm{p}$-Value was significant to ICU days $(\mathrm{p}=0.016)$ and insignificant to MV hrs. $(\mathrm{p}=0.107)$.

*: Statistically significant at $\mathrm{p} \leq 0.05$

Table (8) Relation between arrest and inotropic postoperative in ICU (Inotropic score POD1-3) $(n=45)$.

\begin{tabular}{|c|c|c|c|c|c|c|}
\hline \multirow{3}{*}{$\begin{array}{l}\text { Inotropic } \\
\text { postoperative in } \\
\text { ICU(Inotropic score } \\
\text { POD1-3) }\end{array}$} & \multicolumn{4}{|c|}{ Arrest } & \multirow[t]{3}{*}{$\square^{\square}$} & \multirow[t]{3}{*}{${ }^{\mathrm{FE}_{p}}$} \\
\hline & \multicolumn{2}{|c|}{ No $(n=39)$} & \multicolumn{2}{|c|}{ Yes $(n=6)$} & & \\
\hline & No. & $\%$ & No. & $\%$ & & \\
\hline$\leq \mathbf{2 0}$ & 27 & 69.2 & 1 & 16.7 & $6.112^{*}$ & $0.023^{*}$ \\
\hline$>20$ & 12 & 30.8 & 5 & 83.3 & & \\
\hline
\end{tabular}

$\chi 2$ : Chi square test

FE: Fisher Exact

$\mathrm{p}$ : $\mathrm{p}$ value for comparing between the two studied groups( arrested and inotropic score),I was significant $(\mathrm{P}=0.023)$.

*: Statistically significant at $\mathrm{p} \leq 0.05$ 
Table (9) Relation between arrest and BNP $(n=45)$.

\begin{tabular}{lcccc}
\hline \multirow{2}{*}{ BNP } & \multicolumn{2}{c}{ Arrest } & U & p \\
\cline { 2 - 3 } & No $(\mathbf{n}=\mathbf{3 9})$ & Yes $(\mathbf{n}=\mathbf{6})$ & & \\
\hline Before & & & & \\
Min. - Max. & $80.50-3618.50$ & $125.0-328.0$ & 108.0 & 0.782 \\
Mean \pm SD. & $309.09 \pm 571.68$ & $214.17 \pm 92.48$ & & \\
Median & 177.50 & 183.50 & & \\
After & & & & \\
Min. - Max. & $102.50-4912.0$ & $119.0-2616.50$ & 88.0 & 0.350 \\
Mean + SD. & $997.47 \pm 1322.89$ & $1283.08 \pm 1032.42$ & & \\
Median & 287.0 & 1107.25 & & \\
\hline
\end{tabular}

U: Mann Whitney test

$\mathrm{p}: \mathrm{p}$ value for comparing between the two studied groups $\mathrm{p}$-Value was insignificant

*: Statistically significant at $\mathrm{p} \leq 0.05$

ROC Curve for 24 hours Post-operative BNP in predicting long mechanical ventilation duration (predictor of poor outcome)

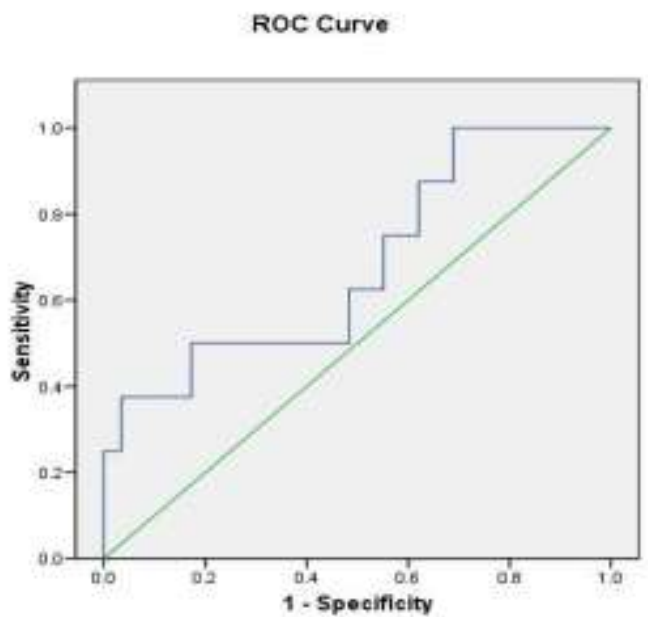

Fig (1) receiving operating characteristics (ROC) curve for BNP cut off among cases. At a cut off value of BNP of $1,096 \mathrm{Pg} / \mathrm{ml}$; sensitivity was $62.5 \%$ and specificity was $52 \%$.

ROC Curve for 24 hours Post-operative BNP in predicting long ICU Stay

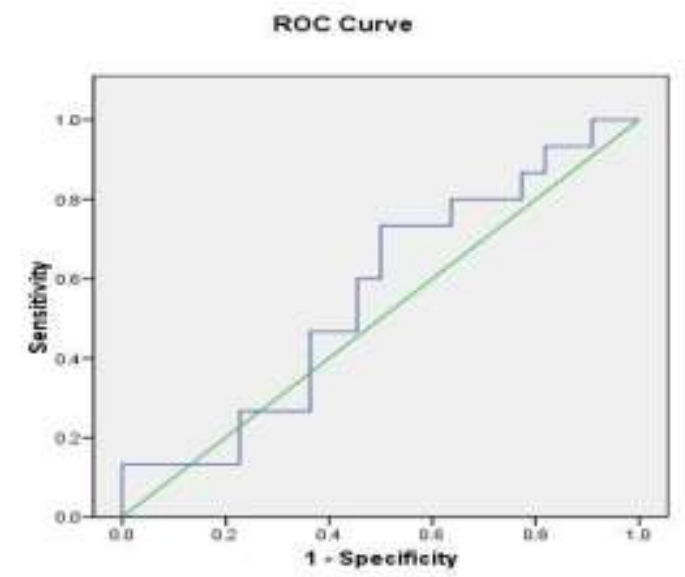

Fig (2) receiving operating characteristics (ROC) curve for BNP cut off among cases. At a cut off value of BNP of $1,096 \mathrm{Pg} / \mathrm{ml}$; sensitivity was $60 \%$ and specificity was $55 \%$.

ROC Curve for 24 hours Post-operative BNP in predicting mortality (Predictor of poor outcome) 


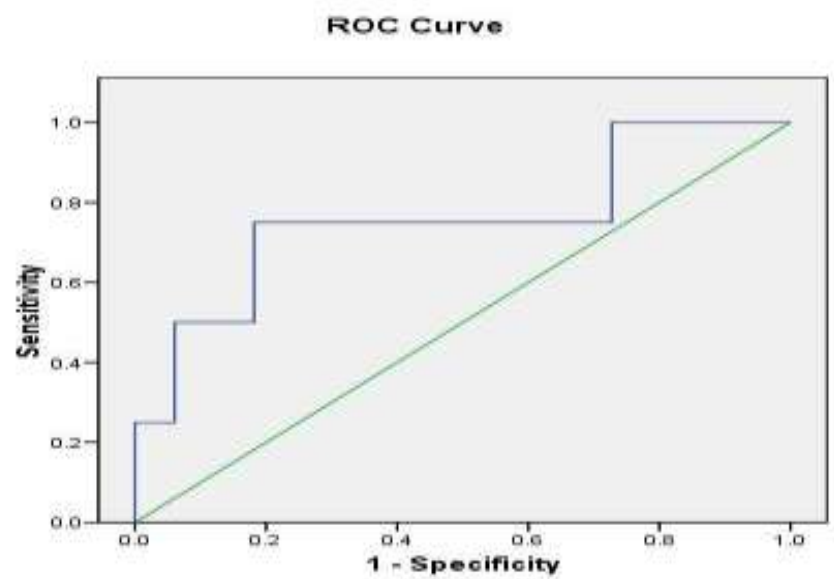

Fig (3) receiving operating characteristics (ROC) curve for BNP cut off among cases. At a cut off value of BNP of $1,482.2 \mathrm{Pg} / \mathrm{ml}$; sensitivity was $75 \%$ and specificity was $81.8 \%$.

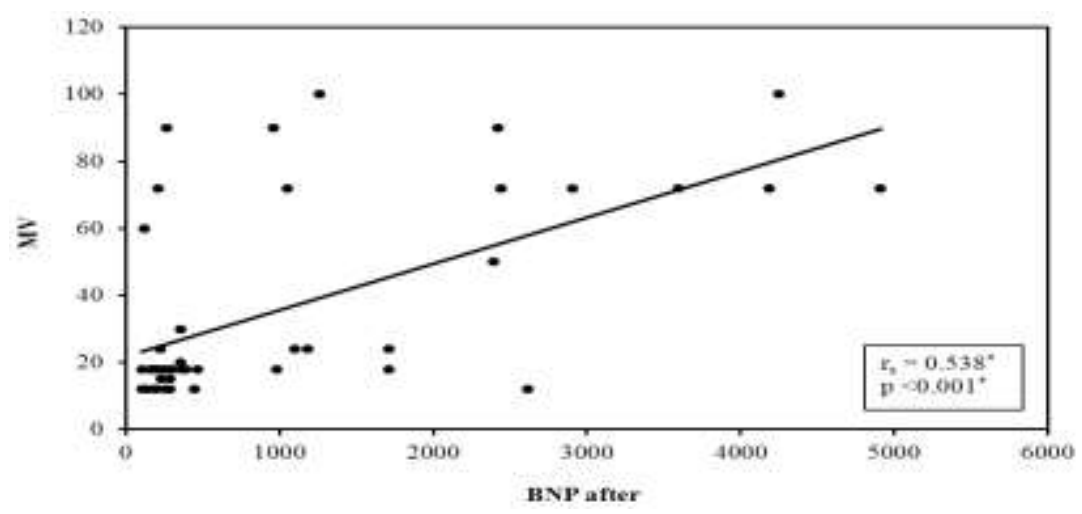

Fig (4) Correlation between BNP after and MV.

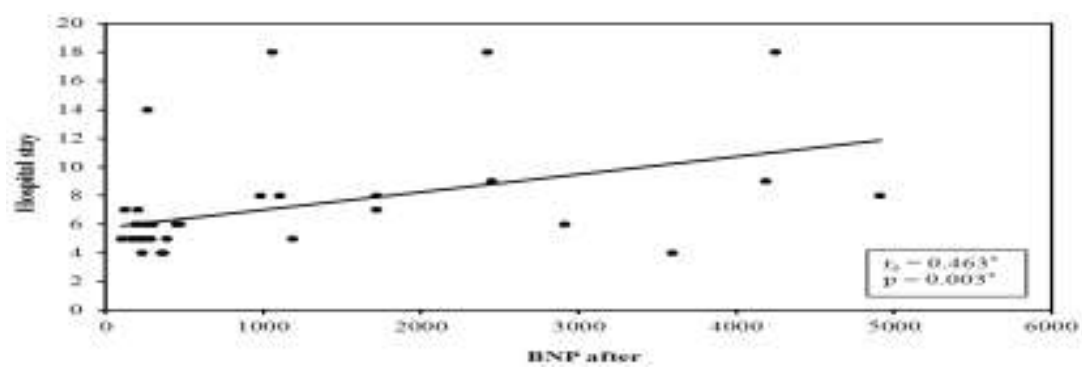

Fig (5) Correlation between BNP after and hospital stay.

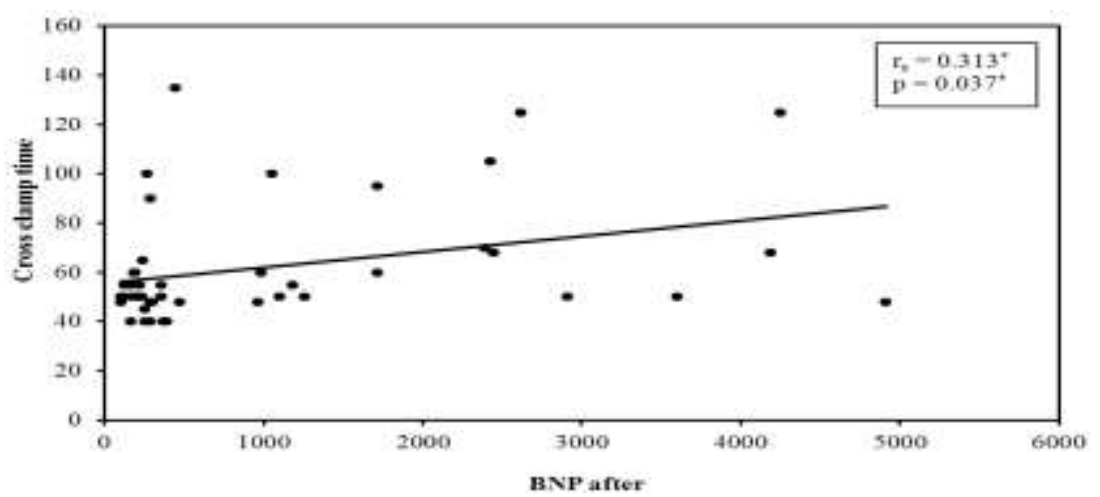

Fig (6) Correlation between BNP after and Cross clamp time $(\mathrm{n}=45)$. 


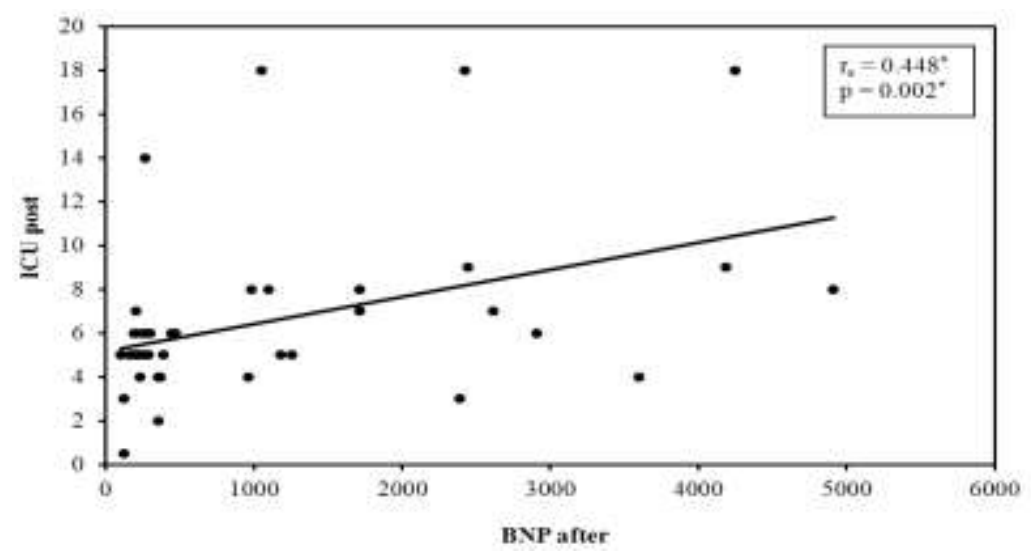

Fig (7) Correlation between BNP after and ICU post op $(n=45)$.

\section{Discussion}

Brain natriuretic peptides determinations might be a useful tool for clinicians caring for infants and children after surgical intervention for congenital heart disease. The aim of this study is to compare perioperative changes in plasma brain natriuretic peptides in children undergoing open heart surgery and to evaluate effect of cardiopulmonary bypass on BNP levels.

The study was conducted on 45 cases in cardiology department - Cairo university Children's hospital and Atfal Maser Chidren's hospital who are previously listed and prepared for open heart surgery in the period from February 2016 to March 2018.

Patients' age ranged from 2 months up to 12 years old. Median age $=25$ months, mean age of cases $=24.98+/-32.20$ months. Male to female ratio was 19:26, males (42.2\%), females $(57.8 \%)$ and Mortality cases recorded were 6.

The results in the present study revealed preoperative BNP assay of the 45 cases with a mean $239.6+/-829.7 \mathrm{pg} / \mathrm{ml}$ (median $=32.0 \mathrm{pg} / \mathrm{ml}$ ) and postoperative BNP assay with a mean 1412.2 +/$1279.1 \mathrm{pg} / \mathrm{ml}$.

In the current study, a comparison between preoperative and postoperative BNP values was done and revealed the total mean difference between pre and postoperative BNP was with a mean $1,172.5838$ $\mathrm{pg} / \mathrm{ml}+/-936.6379 \mathrm{pg} / \mathrm{ml}$ with a significant $\mathrm{p}$-value (0.00).

We have found many studies in agreement with the results in the current study which have showed increase in BNP levels after surgery.

This was agree with retrospective study was conducted at Guangzhou Women and Children's Medical Center. We derived the data from the clinical system databases, 364 eligible consecutive patients undergoing CHD surgery at this hospital between June and December 2014. Patients younger than 18 years with CHD who underwent cardiac surgery were eligible for the study, Plasma NT-proBNP levels were determined in each patient at preoperative, $1 \mathrm{~h}$, $12 \mathrm{~h}$ and $36 \mathrm{~h}$ postoperatively, respectively. The NTproBNP levels were measured with a commercially available fluorescence immunoassayClinical and biochemical data were collected retrospectively form the medical records, including patient demographics (age, weight, gender), the Risk Adjustment in Congenital Heart Surgery, version 1(RACHS-1) score, Cardiopulmonary bypass (CPB) duration, aorta cross clamp (ACC) time and follow-up measurements after surgery: the duration of Intensive Care Unit (ICU). The primary outcome measure was the prolonged ICU stay, as the short-term adverse outcome to estimate prognostic, The results suggested that there was an association between the patientspecific intercepts and prolonged ICU stay $(\beta=0.38$, $\mathrm{SE}=0.11, \quad \mathrm{aOR}=1.46, \quad \mathrm{P}=0.001)$. it showed the higher level of NT-proBNP predicted the higher risk of prolonged ICU stay. Furthermore, compared with before surgery, two effect estimates for both $12 \mathrm{~h}$ and $36 \mathrm{~h}$ postoperative time points were statistically significant $(\mathrm{P}=0.01$ and 0.004 , respectively). This demonstrated that both the mean NT-proBNP exposure level and the time trends, as indicated by the patient-specific intercept and visit-specific slopes, respectively, were associated with prolonged ICU stay.(13).

Sun and colleagues measured BNP levels before and after surgery in 27 infants and children undergoing biventricular repair and 27 patients undergoing palliation of univentricular congenital heart defects. Plasma BNP levels increased after bypass in patients with biventricular defects, but not in patients with univentricular defects (14).

(15) Examined BNP levels before and following cardiac surgery in 25 infants and children with congenital heart disease undergoing complete or palliative repair with the use of cardiopulmonary bypass. BNP levels increased postoperatively, and remained elevated over the first postoperative day. The increase in BNP from baseline to 12 hours was associated with the cardiopulmonary bypass time.

In concordance to the results of the present study, Koch and colleagues measured BNP levels in 65 pediatric patients (age 4 days -17 years, mean age of 3.6), undergoing surgical repair of congenital cardiac defects preoperatively, and for one week after surgery. 
BNP levels increased after surgery (from a median of $31 \mathrm{pg} / \mathrm{ml}$ to $453 \mathrm{pg} / \mathrm{ml}$ ) and remained elevated over the first week, with a bimodal pattern (initial peak at 1.3 days and a second peak at 5.1 days after surgery) (16)

Correlation studies of BNP with core-peripheral temperature (low cardiac output and shock parameters), revealed mean was $4.959+/-1.3492{ }^{\circ} \mathrm{c}$ and after correlating postoperative BNP with coreperipheral temp., $\mathrm{p}$-value was significant $(\mathrm{p}=0.01)$ and correlation coefficient showed low positive correlation $(\mathrm{r}=0.419)$.

[17] studied in his research the relationship between skin temperature and hemodynamic markers of low perfusion states, specifically measures of low cardiac output and his study support the use of skin temperature as a non-invasive marker of hypoperfusion.

However, no comparable studies were found except [17] who recorded core-peripheral temperature measurements in his study (marker of low cardiac output and shock) and found significant correlation with cardiac output $(\mathrm{p}=0.04)$ and systolic blood pressure $(\mathrm{p}=0.001)$.

[18] Reported in his study a significant correlation between postoperative BNP and inotropic score $(r=0.46, p=0.005)$.

Also [19] reported in his study a positive significant correlation between postoperative BNP and inotropic score $(\mathrm{r}=0.34, \mathrm{p}=0.04)$.

(20) Reported in his study a significant correlation between postoperative BNP and inotropic score $(\mathrm{r}=0.46, \mathrm{p}=$ less than 0.001$)$.

In the present study correlation between postoperative BNP and mechanical ventilation duration of all the 45 cases was done and reported significant correlation ( $\mathrm{p}$-value $=0.001$ ) and correlation coefficient showed low positive correlation (r-value $=0.538$ ). The postoperative duration of mechanical ventilation is marker of disease severity and prognosis.

In concordance to our correlation studies, Shih and his colleagues in 2006 reported that the 12-hour BNP level was an independent predictor of the duration of mechanical ventilation and that BNP levels of $\geq 540 \mathrm{pg} / \mathrm{ml}$ predicted mechanical ventilation beyond 48 hours, with a sensitivity of $88.9 \%$ and a specificity of $82.5 \%$.

(21) Also stated that in the bidirectional cardiopulmonary anastomosis patients the 12-hour $\mathrm{BNP} \geq 500 \mathrm{pg} / \mathrm{ml}$ was associated with longer duration Apart from postoperative elevation of BNP values, it was a good predictor of poor outcome. The cut off points of postoperative BNP predicting poor outcome (long mechanical ventilation duration, long ICU stay and mortality) using ROC curve were done.

Regarding the cases who needed long mechanical ventilation duration ( $\geq 48$ hours) were 10 cases (22.2\%) with BNP cut off value of $1,096 \mathrm{pg} / \mathrm{ml}$; sensitivity was $62.5 \%$ and specificity was $52 \%$ ( predictor of poor outcome).

Also done for cases who needed prolonged length of ICU stay ( $\geq 7$ days) and were 18 cases $(40.0 \%)$ with BNP cut off value of $1,096 \mathrm{pg} / \mathrm{ml}$;sensitivity was $60.0 \%$ and specificity was $55 \%$ (predictor of poor outcome).

Also done for mortality cases (6 cases were reported $=13.3 \%$ ) with BNP cut off value of $1,482.2$ $\mathrm{pg} / \mathrm{ml}$; sensitivity was $75 \%$ and specificity was $81.8 \%$ in predicting mortality.

By comparing cut off BNP values in predicting poor outcome with other studies

In a study done by [21], BNP levels were measured before and 2, 12 and 24 hours after surgery in 36 consecutive patients undergoing bidirectional cavopulmonary anastomosis (BCPA) or total cavopulmonary connection. BNP levels were evaluated as predictors of outcome. In the BCPA group, patients with 12 hour BNP $\geq 500 \mathrm{pg} / \mathrm{ml}$ had a longer duration of MV (165+/-149 hrs. vs 20+/-9 hrs., $\mathrm{p}=0.004)$, longer ICU stay $(11+/-7$ days vs $4+/$ 2 days, $\mathrm{p}=0.001)$ and longer hospital stay $(20+/-12$ days vs $9+/-5$ days, $\mathrm{p}=0.003$ ) [21].

Study done by (22) reported that a BNP level of $\geq$ $300 \mathrm{pg} / \mathrm{ml}$ was predictive of death, hospitalization or listing for cardiac transplant and on mechanical ventilation (significant $\mathrm{p}$-value $=0.004$ ).

\section{Conclusion}

ProBrain natriuretic peptides determinations might be a useful tool for clinicians caring for infants and children after surgical intervention for congenital heart disease.

Mechanical ventilation duration, inotropic score calculation as well as Core-peripheral temperature difference are of value when correlated to postoperative BNP measurements.

\section{Recommendation}

We recommend to routinely screen ProBNP cut off values in predicting poor outcome post pediatric cadiac surgery.

\section{References}

[1] M.R.Cowie , G.F. Mendez, :BNP and congestive heart failure. Prog Cardiovasc Dis, vol. 44,PP.293-321,2002.

[2] Ayse Baysal, Ahmet 1 Sasmazel,Ayse Yildirim, The predictive value of plasma B-type natriuretic peptide levels in outcome in children with pulmonary hypertention undergoing congenital heart surgery,Vol. BJANE -164, PP. No.of pages9,2013.

[3] Maisel,():B-Type Natriuretic Peptide Levels: Diagnostic and Prognostic in Congestive Heart Failure,Circulation, Vol. 105, PP.23282331,2002.

[4] Y.M.K. Baghdady, Y.H. Kamel, A.E. Elwan, Nterminal pro-brain natriuretic peptide in 
decompensated ventricular septal defect. Heart Mirror J,Vol.2, PP.36-41,2008.

[5] K.T. Yeo, A.H. Wu, F.S. Apple, Multicenter evaluation of the Roche NT-proBNP assay and comparison to the Biosite Triage BNP Assay. Clin Chim Acta , Vol.338,PP.107-1, 2013.

[6] Luchner, C. Hengstenberg , H. Lwel,():.Nterminal pro-brain natriuretic peptide after myocardial infarction: a marker of cardiorenal function.hypertention, vol .39, PP.99-104, 2002.

[7] J. Doust, R. Lehman, P. Glasziou ,(): The role of BNP testing in heart failure. Am Fam Physician 1, Vol.74, PP.1893-1898,2006.

[8] D.A. Morrow, J.A. de Lemos, Benchmarks for the assessment of novel cardiovascular biomarkers Circulation , Vol.115,PP.949952,2007.

[9] I.S. Anand, L.D. Fisher , Y.T. Chiang, Changes in brain natriuretic peptide and norepinephrine over time and mortality and morbidity in the Valsartan Heart Failure Trial (Val-HeFT). Circulation, Vol. 107, PP. 1278-1283,2003.

[10] M.G. Gaies, J.G. Gurney, A.H. yen, vasoactiveinotropic score as a predictor of morbidity and mortality in infants after cardiopulmonary bypass. Pediatr crit care Med, Vol.11(2), PP.234-238.

[11] Koch M. Singer (): Normal values of B type natriuretic peptide in infants, children, and adolescents. Heart, Vol. 89, PP.875-8,2003.

[12] E. Astrid, A. Alison, G. Sheila, Prognostic value of B-type natriuretic peptide in children with pulmonary hypertension, International Journal of Cardiology, Vol.135, PP. 21-26,2009.

[13] Fangqin Lin 1, Lingling Zheng, Yanqin Cui2, Prognostic value of perioperativeNT-proBNP after corrective surgery forpediatric congenital heart defects BMC Pediatrics , Vol.19, PP.497,2019.

[14] S. Sun, , C. Dominguez, N. A. Mallavaram, "Dysfunction of atrial and B-type natriuretic peptides in congenital univentricular defects." J Thorac Cardiovasc Surg , Vol. 129 (5), PP.110410,2005 .
[15] M. Costello, C. L. Backer, P. A. Checchia, "Alterations in the natriuretic hormone system related to cardiopulmonary bypass in infants with congestive heart failure." Pediatr Cardiol , Vol.25 (4), PP.347-53,2004.

[16] Koch, T. Kitzsteiner, S. Zink, Impact of cardiac surgery on plasma levels of B-type natriuretic peptide in children with congenital heart disease." Int J Cardiol, Vol.25 (4), PP.347-53,2006.

[17] B.M. Schey, D.Y. Williams , T. Bucknall,(): Skin temperature as a non-invasive marker of hemodynamic and perfusion status in adult cardiac surgical patients: an observational study. Intensive crit care nurs. Feb, vol25(1), PP.317,2009 .

[18] J . Hsu, R. Keller, C. Chikovani ,"B-type natriuretic peptide levels predict outcome after neonatal cardiac surgery." J Thorac Cardiovasc Surg:In Press, Vol.25 (4), PP.347-53, 2006.

[19] W.u. Jiunn-ren, I. Chen Chen, zen-kong Dai early elevated B-type natriuretic peptide levels are associated with cardiac dysfunction and poor clinical outcome in pediatric septic patients.Acta cardiol sin , Vol.31(6),PP.485-493,2015.

[20] M. Perez-Piaya, E. Abarca, V. Soler, "Levels of $\mathrm{N}$-terminal-pro-brain natriuretic peptide in congenital heart disease surgery and its value as a predictive biomarker." Interactive cardiovascular and thoracic surgery no, Vol. 12 (3), PP.461-6, 2010.

[21] J.H. Hsu, P.E. Oishi, R.L. Kella, Perioperative Btype natriuretic peptide levels predict outcome after bidirectional cavopulmonary anastomosis and total cavopulmonary connection. J. Thorac. Cardiovasc. Surg, Vol.135, PP.746-753, 2005.

[22] J.F. Price, A.K. Thomas, M. Grenier B-type natriuretic peptide predicts adverse cardiovascular events in paediatric outpatients with chronic left ventricular systolic dysfunction.Circulation , Vol.114, PP.10631069,2006. 